\title{
Associations between vocational students' perceptions of goal structures, mastery goals, and self-efficacy in five subjects-practical relevance as a potential mediator
}

\author{
Lisa Bardach ${ }^{1,2^{*}}$ (@) Vera Popper ${ }^{3}$, Elke Hochfellner ${ }^{4}$ and Marko Lüftenegger ${ }^{2,5}$
}

${ }^{*}$ Correspondence:

lisa.bardach@york.ac.uk

1 Department of Education, University of York, York,

United Kingdom

Full list of author information

is available at the end of the article

\begin{abstract}
Goal structures represent classroom characteristics that are supportive of students' motivation. However, goal structures and their relations with students' motivation have not yet been investigated in the context of vocational education. The present study aims at closing this gap. We investigated the relation between mastery goal structures and the two motivational outcomes mastery goals and self-efficacy in a sample of 1434 Austrian vocational students (64.3\% female) in five subjects (accounting, business administration, English, German, and mathematics). Furthermore, we tested whether the relation between mastery goals and these two motivational outcomes is (partially) mediated by students' perceptions of the practical relevance of instruction in these subjects. Results from multilevel models revealed that goal structures were positively related to mastery goals at the individual student level for all subjects, and for English at the classroom level as well. At both levels, the indirect effect of mastery goal structures on mastery goals mediated by practical relevance was statistically significant for several subjects. In addition, mastery goal structures were positively related to self-efficacy at the individual student level in accounting and at the classroom level in mathematics. Practical relevance mediated the effect of mastery goal structures on self-efficacy in mathematics at the classroom level. Implications of the results for research in vocational education and educational practice are discussed.
\end{abstract}

Keywords: Vocational education, Goal structure, Classroom structure, Mastery goal, Self-efficacy, Practical relevance

\section{Introduction}

Motivation ranks high in importance as a catalyst of students' learning and functions as a gateway to success in students' professional lives. Hence, the study of contexts that promote (or constrain) motivation is essential (Urdan and Schönfelder 2006). One prominent perspective on contextual characteristics that promote students' motivation is achievement goal theory (Kaplan and Maehr 2007; Urdan 2010). Achievement goal theory assumes that contextual characteristics of the classroom-the classroom goal structures-elicit specific patterns of motivational orientations in students (Ames 1992). A large corpus of knowledge exists on goal structures and how they relate to students'

(c) The Author(s) 2019. This article is distributed under the terms of the Creative Commons Attribution 4.0 International License (http://creativecommons.org/licenses/by/4.0/), which permits unrestricted use, distribution, and reproduction in any medium, provided you give appropriate credit to the original author(s) and the source, provide a link to the Creative Commons license, and indicate if changes were made. 
motivation in elementary, middle, and high school, as well as college and university (e.g., Church et al. 2001; Lüftenegger et al. 2014; Shih 2007). However, the role goal structures play in vocational students' motivation has remained unexplored so far.

Thus, in the present study, we sought to investigate the relation between vocational students' ratings of goal structures and two key motivational constructs-mastery goals, which target the development of competence and self-improvement (Elliot 2005; Senko and Dawson 2017), and self-efficacy, i.e., students' beliefs about their capabilities to succeed in tasks and overcome difficulties (Bandura 1997), in five subjects (accounting, business administration, English, German, and mathematics). In addition, the practical relevance of instruction was tested as a potential mediator of the relations between goal structures and both motivational constructs. Practical relevance describes students' perception of whether their teachers links the subject matter to (work) practice and whether they can use the content learned in class in their future lives (e.g., Prenzel et al. 2002).

\section{Achievement goal theory}

What environmental features-such as the class or school-affect students' motivation? Are some of these features more adaptive than others? Achievement goal theory, which figures prominently in educational research, is one theoretical framework that provides answers to these questions. Achievement goal theory includes both a personal and a contextual component. Personal achievement goals, the personal component, refer to competence-relevant purposes or aims that students strive for in achievement settings and learning situations (Elliot et al. 2005). The trichotomous model of achievement goals, the most widely adopted model in research on school-aged students, identifies three types of achievement goals. Students with a mastery goal attach importance to developing new skills and value the process of learning itself (Ames and Archer 1988; Elliot 2005). Students with a performance-approach goal are mainly concerned with outperforming others and demonstrating competence, and students with a performance-avoidance goal strive to avoid performing worse than others and demonstrating incompetence (Elliot 2005; Elliot and Murayama 2008; Grant and Dweck 2003).

Achievement goal theory's contextual component, goal structures, captures specific instructional strategies and goal-related messages that teachers communicate to their students (e.g., Ames 1992; Urdan and Midgley 2003). There are different types of goal structures mirroring the different personal achievement goals students can adopt. First, in a mastery goal structure, teachers emphasize the importance of learning and truly understanding, and that developing competence should be a main goal in class. Second, when a performance-avoidance goal structure prevails, teachers communicate to students that it is essential not to look dumb or demonstrate lower performance than peers. Third, a performance-approach goal structure describes a classroom setting in which students are valued for outperforming peers or showcasing their abilities (e.g., Murayama and Elliot 2009; Miller and Murdock 2007; Patrick et al. 2011; Schwinger and Stiensmeier-Pelster 2011).

Over the past 30 years, a substantial amount of information about the different types of goal structures and their correlates has been accumulated. It has been clearly demonstrated that mastery goal structures are the most beneficial type, as indicated by e.g., links to beneficial motivational patterns, positive emotions, and positive student-teacher 
relationships (e.g., Baudoin and Galand 2017; Lüftenegger et al. 2014; Polychroni et al. 2012). Performance-avoidance goal structures, by contrast, have been identified as the least adaptive type. As such, they have consistently been found to produce a wide array of detrimental outcomes, such as maladaptive motivational patterns (e.g., Schwinger and Stiensmeier-Pelster 2011). Correspondingly, performance-approach goal structures also tend to have maladaptive effects, e.g., in terms of negative relations to motivation (e.g., Murayama and Elliot 2009); although benefits have occasionally been reported as well (e.g., a positive association with autonomous motivation, Peng et al. 2013). Nonetheless, as a mastery goal structure is unambiguously most advantageous for students' adaptive development (for reviews, see e.g., Meece et al. 2006; Urdan and Schönfelder 2006; for a meta-analytic review, see Bardach et al. under review), we focus on mastery goal structures in the present work.

An influential approach to mapping mastery goal structures is the TARGET framework (Ames 1992; Epstein 1988; Lüftenegger et al. 2017). This approach identifies six dimensions of teaching principles and strategies that constitute a classroom's mastery goal structure. The dimensions form the acronym TARGET (task, autonomy, recognition, grouping, evaluation, and time). The task dimension concerns the design of tasks, and how teachers instruct and scaffold students in the process of task completion. Teachers can support students' autonomy by letting students participate in knowledge construction and decisions concerning social matters in class. Recognition captures the procedures and practices used to recognize students for their progress and achievement. Grouping procedures and the value of cooperation among students are described in the grouping dimension. Evaluation comprises teachers' evaluation strategies and includes for instance reliance on an individual reference norm when evaluating students' work. The time dimension captures the use of time, which should be flexible, allowing students to introduce their own questions or topics (Ames 1992; Epstein 1988; Lüftenegger et al. 2017; Patrick et al. 2011).

\section{The relation between mastery goal structures, personal mastery goals, and self-efficacy}

Foremost among the motivational outcomes investigated in research on mastery goal structures are mastery goals. Conceptually, mastery goal structures and mastery goals are closely related: In achievement goal theory, mastery goal structures represent environmental cues that make mastery goals salient on a contextual level and suggest to students that they should be adopted (e.g., Ames 1992; Urdan 2010). Specifically, by being exposed to, interpreting and integrating the mastery-oriented messages that constitute a mastery goal structure into their (motivational) belief systems, students develop and strengthen their own mastery-oriented aims and approaches to learning. As such, critical features of the mastery goal structure, e.g., the focus on learning and teachers' valuing of individual improvement, translate into students' adoption of personal-level goals aligned with the context-level goals that predominate in the classroom setting-i.e., personal mastery goals orienting students towards learning and individual improvement.

In accordance with these theoretical propositions regarding the psychological mechanisms through which mastery goal structures engender mastery goals, an extensive body of empirical evidence supports the robust link between mastery goal structures and 
students' mastery goals (for a meta-analytic review, see Bardach et al. under review). Nonetheless, while mastery goals and how they relate to educational outcomes have previously been investigated in vocational education (e.g., de Koning and Boekaerts 2005), the link between mastery goals and mastery goal structures has not yet been addressed. Vocational education prepares students for different professions. Therefore, students may come to a vocational context with different expectations (in comparison to a more academically-oriented secondary school). It is not clear whether the basic assumption of achievement goal theory concerning the relation between mastery goal structures and mastery goals continues to hold in this unique context. Hence, this study aims to find out whether the well-established association between mastery goal structures and mastery goals can be replicated in a sample of vocational students.

The beneficial motivational effects of a mastery goal structure are not restricted to mastery goals, however. By contrast, mastery goal structures have often been characterized as a "motivational climate" due to their importance for enhancing students' motivation more generally (e.g., Ames 1992; see also e.g., Bardach et al. 2019a; b) and due to their relations to a broad range of other motivational constructs, such as self-efficacy, self-concept, implicit theories, interest, or personal best goals (e.g., Friedel et al. 2007; Khajavy et al. 2018; Lüftenegger et al. 2017). Early research on mastery goal structures and their motivational impact already emphasized that mastery goal structures should particularly influence "how students view their ability" (Ames 1992, p. 263). In fact, a mastery goal structure, which emphasizes that everyone can improve if he or she puts in effort, provides students with numerous opportunities for mastery experiences, thus fostering students' beliefs about their ability to succeed in a given task (i.e., their selfefficacy, Bandura 1997). Further features of mastery goal structures, such as teachers' autonomy-supportive behavior and promotion of students' self-regulation, also give rise to students' favorable self-appraisals of their own ability. Hence, self-efficacy is the second motivational outcome for which we aim to test whether the relation to mastery goal structures holds for vocational students. In the present work, we focus on general selfefficacy as opposed to subject-specific self-efficacy, which has mainly been studied in educational settings and research on (subject-specific) goal structures (e.g., Friedel et al. 2007; Khajavy et al. 2018). General self-efficacy is clearly a more distal outcome than subject-specific self-efficacy; hence, examining whether the relation with self-efficacy generalizes across levels of specificity, and thus affects self-efficacy in a broader sense, represents an even stronger test of the beneficial effects of (subject-specific) goal structures in vocational education. Theoretically, the mechanisms linking mastery goal structures as facilitators of beneficial self-beliefs (e.g., Ames 1992) to self-efficacy should also apply to general self-efficacy-even though the size of the relation might most likely be considerably smaller than for subject-specific self-efficacy.

\section{Practical relevance as potential mediator}

Vocational education relates to the development of practical competence within, or for, a defined work 'domain' (Lucas et al. 2012). Accordingly, we argue that in vocational education, the practical relevance of the subject matter taught and of teachers' instruction is of utmost importance for high-quality learning processes and for students's motivation, including the ongoing motivation to improve one's competence (i.e., mastery goal 
strivings). We understand "practical relevance" as the extent to which students perceive that the subject matter taught by the teacher is of practical relevance for their future lives as well as their perception that the teacher links theoretical content to practical examples (see "relevance of content" as an overlapping construct investigated in vocational education, Prenzel et al. 2002). Underlining the role that practical relevance might play in vocational education, it has been suggested that one important teaching strategy for fostering favorable motivational patterns among vocational students is to draw links between the knowledge learned in vocational school and knowledge useful in the workplace (Berger 2012). In the present study, we explore this relation for the two motivational constructs of mastery goals and self-efficacy. Given that the goal of vocational education is to ultimately prepare students for work in specific professions, students' ongoing motivation to improve their competence in vocational education (i.e., mastery goal strivings) might be inherently linked to the extent to which they experience instruction as practically relevant. Like the link between mastery goal structures and general self-efficacy, the relation between practical relevance and general self-efficacy is more difficult to understand than the link to mastery goals, which are also classroom-focused. However, one possible mechanism behind this relation could be that higher levels of practical relevance in vocational education increase students' feeling of being prepared for their future (working life) and the challenges they might encounter there. This in turn could boost their self-efficacy-not only in a narrow sense, i.e., subject-specific selfefficacy, but also more generally in terms of a broad view that they can handle difficult situations.

Furthermore, we suggest that practical relevance might be a crucial element through which mastery goal structures exert their motivational effects in the specific context of vocational education. A mastery-oriented environment in vocational education might include not only the classical features of a mastery goal structure (e.g., Ames 1992), but also, in order to truly foster students' motivation, teachers might enrich these strategies with further instructional features emphasizing practical relevance. We therefore propose that the positive effect of mastery goal structures on mastery goals and self-efficacy might be (partially) mediated by students' perception of the practical relevance of instruction.

In addition, as knowledge about the context specificity of achievement goal theory is rather underdeveloped (for exceptions, see e.g., Bong 2004; Sparfeldt et al. 2015 for explorations of students' achievement goals in different subjects; for a study on mastery goal structures and their link to achievement goals in mathematics and German, see Bardach et al. 2018), a further contribution of this study lies in the investigation of the link between mastery goal structures, motivational outcomes, and practical relevance in a range of subjects. We include five subjects, two that are specific to vocational education (accounting, business administration) and three that are covered in all Austrian secondary schools (English, German, and mathematics). As such, our study provides highly relevant information both from a theoretical and practical standpoint. Theoretically, we test whether presumably universal tenets of achievement goal theory regarding the relation between the context and personal motivation truly pertain to all of the subjects we investigate. Of practical significance, mastery goal structures are malleable, meaning that teachers can intentionally influence and shape them (e.g., Urdan and Schönfelder 
2006). Hence, finding that the relations between mastery goal structures and outcomes and/or the potential mediating effects of practical relevance differ between (vs. equally apply to all) subjects would indicate the necessity of developing tailored interventions for different subjects (vs. make it possible to identify universal intervention principles).

\section{The present investigation}

To the best of our knowledge, mastery goal structures and their relation to students' motivation have not yet been examined in the context of vocational education. We therefore aim to shed light on the association between vocational students' perceptions of mastery goal structures following the TARGET conceptualization (Ames 1992; Epstein 1988) and motivation in the form of mastery goals and self-efficacy. All of these relations are estimated in multilevel models to account for the nested data structure (with students nested within classes/teachers) and to properly disentangle the individual student versus the classroom level (see e.g., Lüdtke et al. 2009).

Drawing on research with students from educational settings other than vocational school (e.g., Lüftenegger et al. 2017), we hypothesize a positive relation between vocational students' perceptions of mastery goal structures and mastery goals (Hypothesis 1) as well as self-efficacy (Hypothesis 2) at both levels. In addition, we hypothesize that the relations between mastery goal structures and mastery goals as well as the relation between mastery goal structures and self-efficacy are a) partially mediated by practical relevance (Hypothesis 3 for mastery goals as the outcome and Hypothesis 5 for selfefficacy as the outcome) at both levels. We analyze all relations separately for each of five subjects (accounting, business administration, English, German, and mathematics). Although this can be regarded as a considerable strength of the present study, we do not specify a priori assumptions concerning subject-specific patterns of relations between mastery goal structures, the motivational outcomes, and practical relevance, due to a lack of understanding of why and how these relations should differ across subjects. Instead, we assume that the proposed effects (see above) can be found in all subjects.

\section{Method}

\section{Sample}

The sample consisted of 1434 Austrian vocational students $(64.3 \%$ female, mean age $=16.89$ years, $S D=1.47$ years, Grades $10-13)$. The students attended secondary business schools ("Handelsakademien", HAK), a form of higher-level vocational education in the Austrian education system. Secondary business schools in Austria generally last 5 years (Grades 9-13) and provide a complete training program in business management and business administration. Moreover, students in secondary business schools can take a comprehensive final examination ("Matura") at the end of their studies to obtain a university entrance qualification. We investigated five subjects, namely accounting (22.9\%), business administration (20.2\%), mathematics (18.2\%), English (17.6\%), and German, i.e., the official national language of Austria (21.1\%). Trained research assistants collected data in 109 classes. After receiving instructions from the trained research assistants, the students completed an online questionnaire in the school computer lab. The subjects were determined randomly, so that different students within the same class filled out different versions of the questionnaire. We therefore considered the group of 
students within each class assigned to the same questionnaire version as our cluster unit. There were 54 clusters for accounting (average cluster size: 6.09 students), 44 clusters for business administration (average cluster size: 6.57 students), 40 clusters for English (average cluster size: 6.28 students), 50 clusters for German (average cluster size: 5.98 students), and 40 clusters for mathematics (average cluster size: 6.53 students).

\section{Measures}

Self-report scales were employed to assess mastery goal structures, mastery goals, selfefficacy and practical relevance. All items were rated on a scale from "I do not agree at all" (0) to "I agree entirely" (100) and students were asked to indicate their agreement with the items using a slide bar. The items for mastery goal structures, mastery goals, and practical relevance were measured with reference to one of the subjects described above. On the other hand, self-efficacy referred to students' beliefs about their ability to overcome difficulties more generally, without focusing on any particular subject.

\section{Mastery goal structures}

A scale consisting of six items reflecting the six TARGET dimensions was used to assess students' perceptions of mastery goal structures (all items were based on Bergsmann et al. 2013, and Lüftenegger et al. 2014). Following the phrase "In [specific subject, e.g., accounting or German] ..." came statements referring to each dimension, i.e., “... we should try out different ways to learn" for task, or "... we make important decisions together with the teacher" for autonomy, "... the teacher informs me about my learning progress" for recognition, "...we can work on tasks together with classmates if we want" for grouping, "... it does not matter if one makes a mistake" for evaluation, and "... we can bring forward our own interests" for time ( $\alpha$ for accounting $=0.74 ; \alpha$ for business administration $=0.78$; $\alpha$ for English $=0.76 ; \alpha$ for German $=0.79 ; \alpha$ for mathematics $=0.78$ ).

\section{Mastery goals}

We used three items to gauge students' mastery goals. Introduced by the item stem "In [specific subject, e.g., accounting or German] I particularly strive to..., students responded to the following statements: "...learn a lot of new things", "... understand what I am learning", and "... improve my competences" $\left(\alpha_{\mathrm{a}}=0.78 ; \alpha_{\mathrm{be}}=0.78 ; \alpha_{\mathrm{E}}=0.82\right.$; $\left.\alpha_{\mathrm{G}}=0.79 ; \alpha_{\mathrm{m}}=0.73\right)$.

\section{Self-efficacy}

We measured students' self-efficacy with a scale by Schwarzer and Jerusalem (1995). Two items were used, namely "I can solve most problems if I invest the necessary effort", and "Thanks to my resourcefulness, I know how to handle unforeseen situations" $\left(\alpha_{\mathrm{a}}=0.73\right.$; $\alpha_{\mathrm{be}}=0.80 ; \alpha_{\mathrm{E}}=0.81 ; \alpha_{\mathrm{G}}=0.82 ; \alpha_{\mathrm{m}}=0.81$ ).

\section{Practical relevance}

The items measuring students' perceptions of the practical relevance of teachers' instruction were developed in a collaborative project with vocational students carried out by the second and third authors. Two items were developed and employed in this study ("In [specific subject, e.g., accounting or German], the teacher links theoretical 
instruction with practical applications" and "In [specific subject, e.g., accounting or German], I learn something that I can use in the future" $\left(\alpha_{\mathrm{a}}=0.68 ; \alpha_{\mathrm{be}}=0.77 ; \alpha_{\mathrm{E}}=0.67\right.$; $\left.\alpha_{\mathrm{G}}=0.70 ; \alpha_{\mathrm{m}}=0.54\right)$.

\section{Statistical analyses and missing data}

Given the multi-level structure of our data, all models in this study were specified as two-level models using the TYPE $=$ TWOLEVEL command in Mplus 7.3 (Muthén and Muthén 1998-2015). We first set up multilevel confirmatory factor analyses (ML-CFAs) separately for each subject in order to test the adequacy of the measurement models for mastery goal structures and mastery goals. Goodness of fit was assessed with the root mean square error of approximation (RMSEA), the Tucker-Lewis Index (TLI), and the comparative fit index (CFI), in association with the robust maximum likelihood estimator (MLR) as well as the $\chi^{2}$-test for model fit and inspection of parameter estimates. To evaluate the model fit, we relied on rules of thumb for cut-off values reflecting excellent and adequate fit to the data, respectively: (a) CFI and TLI $\geq 0.95$ and 0.90; (b) RMSEA $\leq 0.06$ and 0.08 ( $\mathrm{Hu}$ and Bentler 1999; Marsh et al. 2004). All of these cut-off values should be taken as rough guidelines, not golden rules (Marsh et al. 2004).

Second, multilevel models (MLM) were estimated to investigate the relations between mastery goal structures, students' motivation and the mediating effects of practical relevance separately for each subject (see Fig. 1). All variables were entered both at the individual student level and the classroom level. Group-mean centering was applied to the predictor variables at the individual student level (see e.g., Lüdtke et al. 2009). We chose group-mean centering as we were interested in both within-class and betweenclass effects of students' perceptions of mastery goal structures on the outcomes and group-mean centering allows these two effects to be disentangled. On the classroom level, student ratings of mastery goal structures refer to differences between classes, while on the individual student level, they represent idiosyncratic student perceptions (Lüdtke et al. 2009). Although mastery goal structures capture features of the learning




environment common to all students ("climate construct", see e.g., Marsh et al. 2012; Morin et al. 2014) and the primary level of interest is thus the classroom level, we additionally explored their effects on the individual student level, i.e., individual students' perceptions of teachers' mastery-oriented practices (see also e.g., Karabenick 2004). Put differently, we examined (a) whether individual perceptions of mastery goal structures predict motivational outcomes and whether these effects are mediated by practical relevance, and (b) whether the mean ratings of mastery goal structures of students in classes predict motivational outcomes and whether these effects are mediated by practical relevance-irrespective of individual student perceptions. Statistically, when group-mean centering is applied, the between-class effects of students' aggregated perceptions do not control for interindividual differences in students' perceptions of the learning environment (e.g., their mastery goal structures). By contrast, when grand mean centering is used, the between-class effect can be regarded as a partial effect controlling for the effect of students' individual ratings (Lüdtke et al. 2009).

We set up our MLM and report significance tests for the indirect effects in our mediation analyses relying on Bayes estimation. An advantage of Bayesian methods is that they can deal with asymmetric distributions and thus provide accurate results even if parameters are not normally distributed. The indirect effect in mediation models represents the multiplication of two regression coefficients and is thus always skewed. Therefore, Bayesian estimation, which allows for the handling of non-normal parameters, is particularly well suited for mediation analyses (Van de Schoot et al. 2014; see also Yuan and MacKinnon 2009, for an extensive discussion of Bayesian mediation analysis). Accordingly, the Bayesian Markov chain Monte Carlo (MCMC) method was used to estimate the MLM. Eight Markov chains were requested and a minimum number of 20,000 iterations were specified. The default convergence criterion for Bayesian models is that a proportional scale reduction (PSR) factor is close enough to 1 for each parameter (Gelman and Rubin, 1992; Muthén 2010). In addition, we checked all trace plots for convergence and report posterior predictive p-values (PPP) for all models. PPP values around 0.50 are indicative of a well-fitting model (van de Schoot et al. 2014). To deal with missing data (which ranged between 0 and $0.9 \%$ on the item level for all analyzed variables), full information maximum likelihood estimation (FIML) and Bayesian estimation were used (Enders 2010).

\section{Results}

Model fit indices for the ML-CFAs revealed a (very) good model fit for all scales in accounting, business administration, German, English, and mathematics, hence indicating sound measurement properties for the investigated constructs (see Table 1). Table 1 reports the proportion of the total variance determined to be attributable to the class level (=intraclass correlation, ICC1) and the level of agreement among students' ratings of the class-level constructs (=ICC2; Bliese, 2000). ICC1 values were logically in most cases higher for mastery goal structures than for self-efficacy and mastery goals. Indeed, mastery goal structures can be best understood as a classroom climate construct, which varies between classrooms, whereas mastery goals and self-efficacy represent individual 
Table 1 Multilevel confirmatory factor analysis result: model fit, ICC1 and ICC2 for all scales of mastery goal structures, mastery goals, self-efficacy, and practical relevance in five subjects

\begin{tabular}{|c|c|c|c|c|c|c|c|}
\hline & $x^{2}$ & df & CFI & TLI & RMSEA & ICC1 & ICC2 \\
\hline \multicolumn{8}{|l|}{ Accounting } \\
\hline Mastery goal structure & $56.70^{*}$ & 22 & 0.91 & 0.87 & 0.054 & 0.134 & 0.785 \\
\hline Mastery goals & 0.63 & 3 & 1.00 & 1.02 & 0.000 & 0.047 & - \\
\hline Self-efficacy & - & - & - & - & - & 0.006 & - \\
\hline Practical relevance & - & - & - & - & - & 0.105 & 0.734 \\
\hline \multicolumn{8}{|l|}{ Business economics } \\
\hline Mastery goal structure & 32.45 & 23 & 0.97 & 0.96 & 0.038 & 0.155 & 0.812 \\
\hline Mastery goals & 1.17 & 3 & 1.00 & 1.02 & 0.000 & 0.046 & - \\
\hline Self-efficacy & - & - & - & - & - & 0.027 & - \\
\hline Practical relevance & - & - & - & - & - & 0.129 & 0.776 \\
\hline \multicolumn{8}{|l|}{ English } \\
\hline Mastery goal structure & $46.09^{*}$ & 24 & 0.93 & 0.92 & 0.061 & 0.072 & 0.647 \\
\hline Mastery goals & 1.30 & 2 & 1.00 & 1.00 & 0.000 & 0.039 & - \\
\hline Self-efficacy & - & - & - & - & - & 0.005 & - \\
\hline Practical relevance & - & - & - & - & - & 0.093 & 0.705 \\
\hline \multicolumn{8}{|l|}{ German } \\
\hline Mastery goal structure & $61.81^{*}$ & 24 & 0.92 & 0.90 & 0.072 & 0.085 & 0.686 \\
\hline Mastery goals & 3.01 & 3 & 1.00 & 1.00 & 0.004 & 0.118 & - \\
\hline Self-efficacy & - & - & - & - & - & 0.024 & - \\
\hline Practical relevance & - & - & - & - & - & 0.064 & 0.616 \\
\hline \multicolumn{8}{|l|}{ Mathematics } \\
\hline Mastery goal structure & $47.41^{*}$ & 23 & 0.94 & 0.93 & 0.064 & 0.125 & 0.770 \\
\hline Mastery goals & 1.45 & 4 & 1.00 & 1.01 & 0.000 & 0.039 & - \\
\hline Self-efficacy & - & - & - & - & - & 0.018 & - \\
\hline Practical relevance & - & - & - & - & - & 0.141 & 0.793 \\
\hline
\end{tabular}

$\mathrm{x}^{2}=$ Chi square test of model fit; $\mathrm{TLI}=$ Tucker-Lewis index; $\mathrm{CFI}=$ comparative fit index; $\mathrm{RMSEA}=$ root mean square error of approximation; Note that self-efficacy and practical relevance have only two manifest indicators, wherefore no multilevel confirmatory factor analytic measurement model was set up and no model-fit indices are reported

${ }^{*} p \leq .05$

student characteristics. ICC2 values are interpreted in line with other reliability measures and were in the acceptable to satisfactory range in this study.

For the Bayesian MLMs, all trace plots and PSR factors revealed proper convergence. The PPP values ranged between 0.438 and 0.521 , indicating that all models fit the data rather well. Below, we report the results of the MLMs for the five subjects. Table 2 displays the results from all MLMs (unstandardized and standardized effects).

\section{Accounting}

At the individual student level, mastery goal structures positively predicted mastery goals (unstandardized $\widehat{\beta}=0.21, p<.01$ ) as well as self-efficacy (unstandardized $\widehat{\beta}=0.16$, $p<.05$ ). Furthermore, mastery goal structures positively predicted the practical relevance of instruction (unstandardized $\widehat{\beta}=0.64, p<.01$ ) and practical relevance positively predicted mastery goals (unstandardized $\widehat{\beta}=0.30, p<.01$ ). The indirect effect of mastery goal structures on mastery goals, as mediated by practical relevance, was statistically 
Table 2 Main effects from the multilevel predictive models

\begin{tabular}{|c|c|c|}
\hline Model & Est. (S. D.) & Std. (S. D.) \\
\hline \multicolumn{3}{|l|}{ Accounting } \\
\hline \multicolumn{3}{|l|}{ Classroom-level (L2) effects } \\
\hline Mastery goal structure $\rightarrow$ Mastery goals & $0.19(0.16)$ & $0.32(0.23)$ \\
\hline Mastery goal structure $\rightarrow$ Self-efficacy & $0.02(0.14)$ & $0.07(0.40)$ \\
\hline Mastery goal structure $\rightarrow$ Practical relevance & $0.63(0.13)^{* *}$ & $0.56(0.08) * *$ \\
\hline Practical relevance $\rightarrow$ Mastery goals & $0.10(0.14)$ & $0.17(0.25)$ \\
\hline Practical relevance $\rightarrow$ Self-efficacy & $0.04(0.12)$ & $0.14(0.41)$ \\
\hline \multicolumn{3}{|l|}{ Individual-level (L1) effects } \\
\hline Mastery goal structure $\rightarrow$ Mastery goals & $0.21(0.07)^{* *}$ & $0.18(0.06)^{* *}$ \\
\hline Mastery goal structure $\rightarrow$ Self-efficacy & $0.16(0.07)^{*}$ & $0.14(0.06)^{*}$ \\
\hline Mastery goal structure $\rightarrow$ Practical relevance & $0.64(0.06)^{* *}$ & $0.49(0.04)^{* *}$ \\
\hline Practical relevance $\rightarrow$ Mastery goals & $0.30(0.05)^{* *}$ & $0.32(0.05)^{* *}$ \\
\hline Practical relevance $\rightarrow$ Self-efficacy & $0.06(0.06)$ & $0.07(0.07)$ \\
\hline \multicolumn{3}{|l|}{ Business administration } \\
\hline \multicolumn{3}{|l|}{ Classroom-level (L2) effects } \\
\hline Mastery goal structure $\rightarrow$ Mastery goals & $-0.04(0.14)$ & $-0.09(0.27)$ \\
\hline Mastery goal structure $\rightarrow$ Self-efficacy & $-0.11(0.19)$ & $-0.22(0.34)$ \\
\hline Mastery goal structure $\rightarrow$ Practical relevance & $0.77(0.11)^{* *}$ & $0.74(0.06)^{* *}$ \\
\hline Practical relevance $\rightarrow$ Mastery goals & $0.39(0.13)^{* *}$ & $0.87(0.26)^{* *}$ \\
\hline Practical relevance $\rightarrow$ Self-efficacy & $0.17(0.19)$ & $0.36(0.36)$ \\
\hline \multicolumn{3}{|l|}{ Individual-level (L1) effects } \\
\hline Mastery goal structure $\rightarrow$ Mastery goals & $0.35(0.07)^{* *}$ & $0.31(0.06)^{* *}$ \\
\hline Mastery goal structure $\rightarrow$ Self-efficacy & $0.06(0.08)$ & $0.05(0.07)$ \\
\hline Mastery goal structure $\rightarrow$ Practical relevance & $0.63(0.06)^{* *}$ & $0.52(0.04) * *$ \\
\hline Practical relevance $\rightarrow$ Mastery goals & $0.14(0.06)^{* *}$ & $0.15(0.06) * *$ \\
\hline Practical relevance $\rightarrow$ Self-efficacy & $0.03(0.07)$ & $0.03(0.07)$ \\
\hline \multicolumn{3}{|l|}{ English } \\
\hline \multicolumn{3}{|l|}{ Classroom-level (L2) effects } \\
\hline Mastery goal structure $\rightarrow$ Mastery goals & $0.36(0.19)^{*}$ & $0.50(0.23)^{*}$ \\
\hline Mastery goal structure $\rightarrow$ Self-efficacy & $-0.00(0.23)$ & $-0.00(0.36)$ \\
\hline Mastery goal structure $\rightarrow$ Practical relevance & $0.79(0.18)^{* *}$ & $0.58(0.10)^{* *}$ \\
\hline Practical relevance $\rightarrow$ Mastery goals & $0.10(0.15)$ & $0.17(0.26)$ \\
\hline Practical relevance $\rightarrow$ Self-efficacy & $0.08(0.17)$ & $0.17(0.38)$ \\
\hline \multicolumn{3}{|l|}{ Individual-level (L1) effects } \\
\hline Mastery goal structure $\rightarrow$ Mastery goals & $0.34(0.07)^{* *}$ & $0.33(0.07)^{* *}$ \\
\hline Mastery goal structure $\rightarrow$ Self-efficacy & $0.15(0.10)$ & $0.12(0.07)$ \\
\hline Mastery goal structure $\rightarrow$ Practical relevance & $0.61(0.06)^{* *}$ & $0.52(0.04)^{* *}$ \\
\hline Practical relevance $\rightarrow$ Mastery goals & $0.03(0.06)$ & $0.03(0.07)$ \\
\hline Practical relevance $\rightarrow$ Self-efficacy & $0.06(0.08)$ & $0.05(0.07)$ \\
\hline \multicolumn{3}{|l|}{ German } \\
\hline \multicolumn{3}{|l|}{ Classroom-level (L2) effects } \\
\hline Mastery goal structure $\rightarrow$ Mastery goals & $0.32(0.24)$ & $0.30(0.22)$ \\
\hline Mastery goal structure $\rightarrow$ Self-efficacy & $0.04(0.19)$ & $0.07(0.07)$ \\
\hline Mastery goal structure $\rightarrow$ Practical relevance & $0.80(0.14)^{* *}$ & $0.64(0.08)^{* *}$ \\
\hline Practical relevance $\rightarrow$ Mastery goals & $0.26(0.21)$ & $0.32(0.24)$ \\
\hline Practical relevance $\rightarrow$ Self-efficacy & $-0.07(0.16)$ & $-0.15(0.36)$ \\
\hline \multicolumn{3}{|l|}{ Individual-level (L1) effects } \\
\hline Mastery goal structure $\rightarrow$ Mastery goals & $0.24(0.08)^{* *}$ & $0.20(0.07)^{* *}$ \\
\hline Mastery goal structure $\rightarrow$ Self-efficacy & $0.08(0.08)$ & $0.07(0.07)$ \\
\hline
\end{tabular}


Table 2 (continued)

\begin{tabular}{lll}
\hline Model & Est. (S. D.) & Std. (S. D.) \\
\hline Mastery goal structure $\rightarrow$ Practical relevance & $0.77(0.07)^{* *}$ & $0.58(0.04)^{* *}$ \\
Practical relevance $\rightarrow$ Mastery goals & $0.21(0.06)^{* *}$ & $0.23(0.07)^{* *}$ \\
Practical relevance $\rightarrow$ Self-efficacy & $0.08(0.07)$ & $0.10(0.08)$ \\
Mathematics & & \\
Classroom-level $(L 2)$ effects & & \\
Mastery goal structure $\rightarrow$ Mastery goals & $0.23(0.17)$ & $0.32(0.23)$ \\
Mastery goal structure $\rightarrow$ Self-efficacy & $0.35(0.17)^{* *}$ & $0.72(0.28)^{* *}$ \\
Mastery goal structure $\rightarrow$ Practical relevance & $0.83(0.16)^{* *}$ & $0.67(0.09)^{* *}$ \\
Practical relevance $\rightarrow$ Mastery goals & $0.32(0.13)^{*}$ & $0.57(0.21)^{*}$ \\
Practical relevance $\rightarrow$ Self-efficacy & $-0.29(0.14)^{*}$ & $-0.76(0.27)^{*}$ \\
Individual-level $(L 1)$ effects & & $0.22(0.07)^{* *}$ \\
Mastery goal structure $\rightarrow$ Mastery goals & $0.26(0.08)^{* *}$ & $0.10(0.07)$ \\
Mastery goal structure $\rightarrow$ Self-efficacy & $0.12(0.08)$ & $0.56(0.04)^{* *}$ \\
Mastery goal structure $\rightarrow$ Practical relevance & $0.72(0.07)^{* *}$ & $0.29(0.06)^{* *}$ \\
Practical relevance $\rightarrow$ Mastery goals & $0.26(0.06)^{* *}$ & $0.03(0.08)$ \\
Practical relevance $\rightarrow$ Self-efficacy & $0.02(0.07)$ &
\end{tabular}

Est. = unstandardized parameter estimate; S. D. = Bayesian Posterior Standard Deviation; Std. = standardized parameter estimate

${ }^{*} p \leq .05 ; * * 0.01$

significant (unstandardized $\widehat{\beta}=0.19, p<.01$ ). At the classroom level, mastery goal structures predicted practical relevance (unstandardized $\widehat{\beta}=0.63, p<.01$ ).

\section{Business administration}

For business administration, we found positive relations between mastery goal structures and mastery goals (unstandardized $\widehat{\beta}=0.35, p<.01$ ), mastery goal structures and practical relevance (unstandardized $\widehat{\beta}=0.63, p<.01$ ), as well as practical relevance and mastery goals (unstandardized $\widehat{\beta}=0.14, p<.01$ ). Moreover, the results revealed a statistically significant positive indirect effect of mastery goal structures on mastery goals, as mediated by practical relevance (unstandardized $\widehat{\beta}=0.09, p<.01$ ). At the classroom level, mastery goal structures were positively related to practical relevance (unstandardized $\widehat{\beta}=0.77, p<.01$ ) and practical relevance was positively related to mastery goals (unstandardized $\widehat{\beta}=0.39, p<.01$ ). Furthermore, the indirect effect of mastery goal structures on mastery goals, as mediated by practical relevance, was statistically significant (unstandardized $\widehat{\beta}=0.30, p<.01$ ).

\section{English}

At the individual student level, mastery goal structures positively predicted mastery goals (unstandardized $\widehat{\beta}=0.34, p<.01$ ). Moreover, the results showed that mastery goal structures positively predicted the practical relevance of instruction (unstandardized $\widehat{\beta}=0.61, p<.01$, respectively). The same pattern emerged at the classroom level, i.e., mastery goal structures positively predicted mastery goals and the practical relevance 
of instruction (unstandardized $\widehat{\beta}=0.36, p<.05$, and unstandardized $\widehat{\beta}=0.79 p<.01$, respectively). None of the indirect effects were statistically significant.

\section{German}

The results for German indicated that at the individual student level, mastery goal structures positively predicted mastery goals (unstandardized $\widehat{\beta}=0.24, p<.01$ ). Furthermore, mastery goal structures positively predicted practical relevance (unstandardized $\widehat{\beta}=0.77, p<.01$ ), and practical relevance positively predicted mastery goals (unstandardized $\widehat{\beta}=0.21, p<.01$ ). Furthermore, the indirect effects of mastery goal structures on the motivational constructs, mediated by practical relevance, were statistically significant for mastery goals (unstandardized $\widehat{\beta}=0.16, p<.01$ ). At the classroom level, mastery goal structures positively predicted the practical relevance of instruction (unstandardized $\widehat{\beta}=0.80, p<.01)$.

\section{Mathematics}

Finally, in mathematics, mastery goal structures positively predicted mastery goals (unstandardized $\widehat{\beta}=0.26, p<.01$ ) and practical relevance (unstandardized $\widehat{\beta}=0.72$, $p<.01$ ), while mastery goals were positively predicted by practical relevance (unstandardized $\widehat{\beta}=0.26, p<.01$ ) at the individual student level. Furthermore, the indirect effect of mastery goal structures on mastery goals, as mediated by practical relevance, proved to be statistically significant (unstandardized $\widehat{\beta}=0.19, p<.01$ ). At the classroom level, mastery goal structures positively predicted self-efficacy (unstandardized $\widehat{\beta}=0.35$, $p<.01)$. In addition, mastery goal structures were positively related to practical relevance (unstandardized $\widehat{\beta}=0.83, p<.01$ ). Practical relevance was positively related to mastery goals (unstandardized $\widehat{\beta}=0.32, p<.05$ ), but negatively related to self-efficacy (unstandardized $\widehat{\beta}=-0.29, p<.05)$. The indirect effect of mastery goal structures on mastery goals, as mediated by practical relevance, was positive and statistically significant (unstandardized $\widehat{\beta}=0.26, p<.05$ ), while the indirect effect of mastery goal structures on self-efficacy, as mediated by practical relevance, was negative and statistically significant (unstandardized $\widehat{\beta}=-0.24, p<.05$ ).

\section{Discussion}

The present study examined the relation between mastery goal structures and vocational students' mastery goals and self-efficacy. Moreover, it shed light on whether these effects are (partially) mediated by practical relevance. The study's findings indicate that in all subjects, mastery goal structures were positively related to mastery goals at the individual student level, with the strongest relations occurring for business administration and English. These results concerning the direct effects of mastery goal structures on mastery goals at the individual student level supported our hypotheses and are in line with findings from other educational contexts (e.g., Lüftenegger et al. 2017, for a study in regular secondary education). In addition, they add to our existing knowledge on the subject-specificity of a mastery goal structure's relation to achievement goals, which has so far mainly focused on the individual student level (e.g., Anderman and Midgley 1997; Bong 2004). Moreover, we found that mastery goal structures positively predicted selfefficacy at the individual student level for accounting, hence replicating the findings of 
studies conducted in educational contexts other than vocational schools for this subject (e.g., Friedel et al. 2007). The fact that more statistically significant effects emerged for the motivational outcome of mastery goals than for self-efficacy and that the effects for mastery goals were larger in magnitude might be due to the way we assessed selfefficacy. While all other measures referred to one of the five subjects, self-efficacy was operationalized as a student's general perception that he or she can handle difficult situations and is able to solve problems by putting forth effort. Nonetheless, for accounting, it was found that the extent to which a student perceives instruction in accounting as mastery-oriented fosters not only his or her mastery goals, but also positive general selfbeliefs. Although this finding is based on one study and one sample and requires replications before confident conclusions can be reached, we suggest that one possible reason could be that in the vocational schools in our sample, accounting might be a subject that students value particularly highly and attach importance to. Due to the personal meaning of this subject, the positive and mastery-oriented experiences a student has in class could therefore affect his or her general self-efficacy.

Results at the individual student level further revealed that mastery goal structures positively predicted the practical relevance of instruction, which in turn positively predicted mastery goals for all subjects except English. On the other hand, for self-efficacy, no relation with practical relevance occurred. Importantly, practical relevance partially mediated the effect of mastery goal structures on mastery goals for accounting, business administration, German, and mathematics. These findings concerning the mediating effect highlight the crucial role that linking (mastery-focused) instruction to practice and students' future (working) lives plays for individual vocational students' motivation.

At the classroom level, the hypothesized positive direct effects of mastery goal structures on personal mastery goals were restricted to the subject of English, and the hypothesized positive direct effects of mastery goal structures on self-efficacy to the subject of mathematics. As such, class-average mastery goal pursuit and general self-efficacy seem to be affected by mastery-oriented instruction in English and mathematics, respectively. Interestingly, the classroom-level effects solely occurred for the "classical" and widely taught subjects of English and mathematics and not for business administration and accounting, the two subjects specific to vocational education. However, just as at the individual student level, the results for the classroom level showed that mastery goal structures positively predicted practical relevance. In addition, we found that practical relevance positively predicted mastery goals in business administration and mathematics. Moreover, our results revealed a statistically significant positive indirect effect of mastery goal structures on mastery goals, mediated by practical relevance, for mathematics and business administration, although the direct effects of mastery goal structures on mastery goals failed to reach statistical significance. Surprisingly, for mathematics, practical relevance negatively predicted self-efficacy, and the indirect effect of mastery goal structures on self-efficacy (mediated by practical relevance) was also negative. The findings concerning self-efficacy clearly raise questions-how can we explain the fact that classes in which students more strongly agree that the subject matter learned in mathematics is useful for their future and that their teachers connect theory with practice tend to score lower on measures of general self-efficacy? It could be that further variables-not tested here-can aid in unraveling the mechanisms underlying 
this unexpected finding. For instance, consider (class-average) mathematics achievement. While students in classes with a low average achievement level in mathematics might acknowledge that the content learned in mathematics is relevant and that their teacher attempts to link theoretical explanations with practical inputs, these realizations could have a detrimental effect on their self-efficacy. When combined with low or even deficient achievement levels, practical relevance might discourage and overwhelm students and decrease their-perhaps already fragile-beliefs in their own capabilities. This explanation is of course purely speculation and we highly recommend that future studies investigate the interplay between practical relevance, self-efficacy, and mastery goals structures to find out whether our finding can be replicated in further samples, and if so, which factors (such as achievement) might account for this effect.

\section{Practical implications}

Our findings on the relation between mastery goal structures and the two motivational constructs hold practical implications. They emphasize the value of structuring class in alignment with a mastery goal structure in order to foster individual vocational students' motivation. Crucially, the TARGET framework, on which our conceptualization of mastery goal structures rests, provides teachers with a toolbox of related instructional strategies (e.g., concerning the design of tasks, autonomy-supportive behavior, recognition and evaluation practices, e.g., Kaplan and Maehr 2007; Lüftenegger et al. 2017). In light of our results on the positive effect of mastery goal structures on mastery goals, and to a lesser extent, i.e., only for accounting, on self-efficacy at the individual student level, it appears worthwhile to encourage teachers in vocational education to focus on creating mastery goal structures. Moreover, our findings support the notion that the practical relevance of instruction appears to be especially important for students' academic life in vocational education and should therefore be fostered (e.g., Berger 2012; Prenzel et al. 2002) as it can be linked to mastery-oriented instruction and motivation or even transmits the effect of the former to the latter. Hence, we conclude that teachers in vocational education would do well to emphasize both mastery goal structures and practical relevance. As such, we argue on the one hand for the application of achievement goal theory's basic tenets (i.e., establish mastery goal structures to elicit mastery goals) and on the other hand, encourage practitioners to adapt achievement goal theory to the specific context of vocational education by additionally paying attention to the practical relevance of instruction.

\section{Limitations and future directions for research}

The results presented above must be considered in light of several limitations. The direction of effects we propose, with mastery goal structures predicting the motivational constructs, is theoretically sound and has received empirical support in previous studies (see e.g., Lüftenegger et al. 2014). However, we are also aware that the use of cross-sectional data is a limitation of our study. Therefore, future work in this direction should employ longitudinal designs that allow for more confident conclusions regarding causality. Furthermore, even though mastery goals and self-efficacy represent two key motivational constructs, we see a need to further expand classroom goal structure's motivational 
nomological network in the context of vocational education by including more motivational outcomes, e.g., self-concept or implicit theories (e.g., Khajavy et al. 2018). Lastly, practical relevance was the only potential mediator we considered in our study. Thus, future research would do well to investigate a range of further potential mediators, such as students' achievement or teachers' relatedness with students (e.g., Klassen et al. 2012).

\section{Conclusions}

The present research was designed to investigate the effects of mastery goal structures on students' self-efficacy beliefs and their adoption of mastery goals, and to empirically test whether these effects are (partially) mediated by the practical relevance of instruction. Aligned with research on mastery goal structures in other educational settings, our work provides evidence for the adaptiveness of mastery goal structures for individual students' motivation, particularly with regard to mastery goals. Moreover, we found support for mastery goal structure's positive association with practical relevance at both levels, and, for some subjects, practical relevance mediated the effects of mastery goal structures on mastery goals (partial mediation for four subjects at the individual student level, total mediation for two subjects at the classroom level). Conducting all analyses separately for five subjects-accounting, business administration, German, English, and mathematics-allowed to gain insights into which effects between the context (i.e., mastery goals) and personal motivational patterns (i.e., mastery goals and self-efficacy) in our study might best be conceived of as subject-specific and which effects seem to generalize across subjects in vocational school. While the results of our study hold practical implications for structuring class in vocational education, our work also raises a number of opportunities for future research on vocational students' perceptions of mastery goal structures and points towards the promise of paying attention to contextual influences on vocational students' motivation.

Acknowledgements

Not applicable.

\section{Authors' contributions}

LB analyzed the data and wrote large parts of the manuscript. VP and EH designed the study and organized the data collection. ML was a major contributor in writing the manuscript and in analyzing the data. All authors read and approved the final manuscript.

\footnotetext{
Author information

Lisa Bardach is a postdoctoral researcher working at the Department of Education, University of York. Her primary research topics include teachers and students' motivation and contextual motivational features (goal structures), teacher selection and teacher effectiveness, and socio-emotional aspects of learning and instruction.
}

Vera Popper obtained her Ph.D. in educational psychology. Currently, she works as a consultant and evaluator.

Elke Hochfellner received her Ph.D. in economics and works as a process manager of vocational schools in Vienna.

Marko Lüftenegger obtained a Ph.D. in educational psychology and holds a position as assistant professor of developmental and educational psychology at the Centre of Teacher Education at the University of Vienna. His research and teaching focus on motivation and emotions in education, high ability and giftedness, classroom environments that facilitate students' (positive) development and the evaluation of educational programs. He is the leader of several third party funded projects (e.g. "Financial Literacy in Secondary Schools" or "Gifted Students' Achievement Goals"). Publication list: http://homepage.univie.ac.at/marko.lueftenegger/publikationen.html.

Funding

Not applicable 
Availability of data and materials

The datasets used and/or analyzed during the current study are available from the corresponding author on reasonable request.

\section{Competing interests}

The authors declare that they have no competing interests.

\section{Author details}

${ }^{1}$ Department of Education, University of York, York, United Kingdom. ${ }^{2}$ Department of Applied Psychology: Work, Education, and Economy, Faculty of Psychology, University of Vienna, Vienna, Austria. ${ }^{3}$ Dynamic Balancing Consulting, Vienna, Austria. ${ }^{4}$ Kaufmännische Schulen des BFI Wien, Vienna, Austria. ${ }^{5}$ Department for Teacher Education, Centre for Teacher Education, University of Vienna, Vienna, Austria.

Received: 14 January 2019 Accepted: 28 May 2019

Published online: 04 June 2019

\section{References}

Ames C (1992) Classrooms: goals, structures, and student motivation. J Educ Psychol 84:261-267. https://doi. org/10.1037/0022-0663.84.3.261

Ames C, Archer J (1988) Achievement goals in the classroom: students' learning strategies and motivation processes. J Educ Psychol 80:260-267. https://doi.org/10.1037/0022-0663.80.3.260

Anderman EM, Midgley C (1997) Changes in achievement goal orientations, perceived academic competence, and grades across the transition to middle-level schools. Contemp Educ Psychol 22:269-298. https://doi.org/10.1006/ ceps.1996.0926

Bandura A (1997) Self-efficacy: the exercise of control. W.H. Freeman, New York

Bardach L, Yanagida T, Schober B, Lüftenegger M (2018) Within-class consensus on classroom goal structures-relations to achievement and achievement goals in mathematics and language classes. Learn Individ Differ 67:68-90. https:// doi.org/10.1016/j.lindif.2018.07.002

Bardach L, Lüftenegger M, Yanagida T, Schober B, Spiel C (2019a) The role of within-class consensus on mastery goal structures in predicting socio-emotional outcomes. Br J Educ Psychol 89:239-258. https://doi.org/10.1111/ bjep. 12237

Bardach L, Lüftenegger M, Yanagida T, Spiel C, Schober B (2019b) Achievement or agreement—which comes first? Clarifying the temporal ordering of achievement and within-class consensus on classroom goal structures. Learn Instr 61:72-83. https://doi.org/10.1016/j.learninstruc.2019.01.003

Bardach L, Oczlon S, Pietschnig J, Lüftenegger M. (under review). Has achievement goal theory been right? A metaanalysis of the relation between goal structures and personal achievement goals

Baudoin N, Galand B (2017) Effects of classroom goal structures on student emotions at school. Int J Educ Res 86:13-22. https://doi.org/10.1016/j.ijer.2017.08.010

Berger $J \mathrm{~L}$ (2012) Uncovering vocational students' multiple goal profiles in the learning of professional mathematics: differences in learning strategies, motivational beliefs and cognitive abilities. Educ Psychol 32:405-425. https://doi. org/10.1080/01443410.2012.674663

Bergsmann EM, Lüftenegger M, Jöstl G, Schober B, Spiel C (2013) The role of classroom structure in fostering students' school functioning: a comprehensive and application-oriented approach. Learn Individ Differ 26:131-138. https:// doi.org/10.1016/j.lindif.2013.05.005

Bliese PD (2000) Within-group agreement, non-independence, and reliability: implications for data aggregation. In: Klein KJ, Kozlowski SW (eds) Multilevel theory, research, and methods in organizations. Jossey-Bass, San Francisco, pp 349-381

Bong M (2004) Academic motivation in self-efficacy, task value, achievement goal orientations, and attributional beliefs. J Educ Res 97:287-298. https://doi.org/10.3200/joer.97.6.287-298

Church MA, Elliot AJ, Gable SL (2001) Perceptions of classroom environment, achievement goals, and achievement outcomes. J Educ Psychol 93:43-54. https://doi.org/10.1037/0022-0663.93.1.43

de Koning E, Boekaerts M (2005) Determinants of students'school-identification in secondary vocational education. Eur J Psychol Educ 20:289-308. https://doi.org/10.1007/BF03173558

Elliot AJ (2005) A conceptual history of the achievement goal construct. In: Elliot AJ, Dweck CS (eds) Handbook of competence and motivation. Guilford Press, New York, pp 52-72

Elliot AJ, Murayama K (2008) On the measurement of achievement goals: critique, illustration, and application. J Educ Psychol 100(3):613-628. https://doi.org/10.1037/0022-0663.100.3.613

Elliot AJ, Shell MM, Henry KB, Maier MA (2005) Achievement goals, performance contingencies, and performance attainment: an experimental test. J Educ Psychol 97:630-640. https://doi.org/10.1037/0022-0663.97.4.630

Enders CK (2010) Applied missing data analysis. Guilford, New York

Epstein JL (1988) Effective schools or effective students: dealing with diversity. In: Haskins R, MacRae D (eds) Policies for America's public schools: teacher, equity and indicators. Ablex, Norwood, pp 89-126

Friedel J, Cortina KS, Turner JC, Midgley C (2007) Achievement goals, efficacy beliefs and coping strategies in mathematics. The roles of perceived parent and teacher goal emphases. Contemp Educ Psychol 32:434-458. https://doi. org/10.1016/j.cedpsych.2006.10.009

Gelman A, Rubin DB (1992) Inference from iterative simulation using multiple sequences. Stat Sci 7:457-472

Grant H, Dweck CS (2003) Clarifying achievement goals and their impact. J Pers Soc Psychol 85:541-553. https://doi. org/10.1037/0022-3514.85.3.541

Hu L, Bentler PM (1999) Cutoff criteria for fit indexes in covariance structure analysis: conventional criteria versus new alternatives. Struct Equ Modeling 6:1-55. https://doi.org/10.1080/10705519909540118 
Kaplan A, Maehr ML (2007) The contributions and prospects of goal orientation theory. Educ Psychol Rev 19:141-184. https://doi.org/10.1007/s10648-006-9012-5

Karabenick SA (2004) Perceived achievement goal structure and college student help seeking. J Educ Psychol 96:569581. https://doi.org/10.1037/0022-0663.96.3.569

Khajavy GH, Bardach L, Hamedi SM, Lüftenegger M (2018) Broadening the nomological network of classroom goal structures using doubly latent multilevel modeling. Contemp Educ Psychol 52:61-73. https://doi.org/10.1016/j. cedpsych.2017.10.004

Klassen RM, Perry NE, Frenzel AC (2012) Teachers'relatedness with students: an underemphasized component of teachers' basic psychological needs. J Educ Psychol 104:150-165. https://doi.org/10.1037/a0026253

Lucas B, Spencer E, Claxton G (2012) How to teach vocational education: a theory of vocational pedagogy. City \& Guilds Centre for Skills Development, London

Lüdtke O, Robitzsch A, Trautwein U, Kunter M (2009) Assessing the impact of learning environments: how to use student ratings of classroom or school characteristics in multilevel modelling. Contemp Educ Psychol 34:120-131. https:// doi.org/10.1016/j.cedpsych.2008.12.001

Lüftenegger M, van de Schoot R, Schober B, Finsterwald M, Spiel C (2014) Promotion of students' mastery goal orientations: does TARGET work? Educ Psychol 34:451-469. https://doi.org/10.1080/01443410.2013.814189

Lüftenegger M, Tran U, Bardach L, Schober B, Spiel C (2017) Measuring a classroom mastery goal structure using the TARGET dimensions: development and validation of a classroom goal structure scale. Zeitschrift für Psychologie 225:64-75. https://doi.org/10.1027/2151-2604/a000277

Marsh HW, Hau K-T, Wen Z (2004) In search of golden rules: comment on hypothesis-testing approaches to setting cutoff values for fit indexes and dangers in overgeneralizing Hu and Bentler's (1999) findings. Struct Equ Model 11:320-341. https://doi.org/10.1207/s15328007sem1103_2

Marsh HW, Lüdtke O, Nagengast B, Trautwein U, Morin AJS, Abduljabbar AS, Köller O (2012) Classroom climate and contextual effects: conceptual and methodological issues in the evaluation of group-level effects. Educ Psychol 47:106-124. https://doi.org/10.1080/00461520.2012.670488

Meece J, Anderman E, Anderman L (2006) Classroom goal structure, student motivation, and academic achievement. Annu Rev Psychol 57:487-503. https://doi.org/10.1146/annurev.psych.56.091103.070258

Miller AD, Murdock TB (2007) Modeling latent true scores to determine the utility of aggregate student perceptions as classroom indicators in HLM: the case of classroom goal structures. Contemp Educ Psychol 32:83-104. https://doi. org/10.1016/j.cedpsych.2006.10.006

Morin AJS, Marsh HW, Nagengast B, Scalas LF (2014) Doubly latent multilevel analyses of classroom climate: an illustration. J Exp Educ 82:143-167. https://doi.org/10.1080/00220973.2013.769412

Murayama K, Elliot AJ (2009) The joint influence of personal achievement goals and classroom goal structures on achievement-relevant outcomes. J Educ Psychol 101:432-447. https://doi.org/10.1037/a0014221

Muthén B. (2010). Bayesian analysis in Mplus: a brief introduction. Unpublished manuscript. http://www.statmodel.com/ download/IntroBayesVersion\%201.pdf. Retrieved 12 Mar 2019

Muthén BO, Muthén LK (1998-2015). Mplus (version 7.3). Los Angeles: Muthén \& Muthén

Patrick H, Kaplan A, Ryan AM (2011) Positive classroom motivational environments: convergence between mastery goal structure and classroom social climate. J Educ Psychol 103:367-382. https://doi.org/10.1037/a002331

Peng S-L, Cherng B-L, Chen H-C, Lin Y-Y (2013) A model of contextual and personal motivations in creativity: how do the classroom goal structures influence creativity via self-determination motivations? Think Skills Creat 10:50-67. https ://doi.org/10.1016/j.tsc.2013.06.004

Polychroni F, Hatzichristou C, Sideridis G (2012) The role of goal orientations and goal structures in explaining classroom social and affective characteristics. Learn Individ Differ 22:207-217. https://doi.org/10.1016/j.lindif.2011.10.005

Prenzel M, Kramer K, Drechsel B (2002) Self-determined and interested learning in vocational education. In K. Beck (Ed.) Teaching-learning processes in vocational education. Foundations of modern training programs (pp. 43-68). Frankfurt a. M.: Lang

Schwarzer R, Jerusalem M (1995) Generalized self-efficacy scale. In: Weinman J, Wright S, Johnston M (eds) Measures in health psychology: a user's portfolio. Causal and control beliefs. Nfer-Nelson, Windsor, pp 35-37

Schwinger M, Stiensmeier-Pelster J (2011) Performance-approach and performance-avoidance classroom goals and the adoption of personal achievement goals. Br J Educ Psychol 81:680-699. https://doi.org/10.111 1/j.2044-8279.2010.02012.x

Senko C, Dawson B (2017) Performance-approach goal effects depend on how they are defined: meta-analytic evidence from multiple educational outcomes. J Educ Psychol 109:574-598. https://doi.org/10.1037/edu0000160

Shih S (2007) The role of motivational characteristics in Taiwanese sixth graders' Avoidance of help seeking in the classroom. Elem Sch J 107(5):473-495. https://doi.org/10.1086/518624

Sparfeldt JR, Brunnemann N, Wirthwein L, Buch SR, Schult J, Rost DH (2015) General versus specific achievement goals: a re-examination. Learn Individ Differ 43:170-177. https://doi.org/10.1016/j.lindif.2015.08.022

Urdan T (2010) The challenges and promise of research on classroom goal structures. In: Meece J, Eccles J (eds) Handbook of research on classroom motivation. Erlbaum, Mahwah, pp 92-108

Urdan T, Midgley C (2003) Changes in the perceived classroom goal structure and pattern of adaptive learning during early adolescence. Contemp Educ Psychol 28:524-551. https://doi.org/10.1016/S0361-476X(02)00060-7

Urdan T, Schönfelder E (2006) Classroom effects on student motivation: goal structures, social relationships, and competence beliefs. J Sch Psychol 44:331-349. https://doi.org/10.1016/j.jsp.2006.04.003

Van de Schoot R, Kaplan D, Denissen J, Asendorpf JB, Neyer FJ, van Aken MA (2014) A gentle introduction to Bayesian analysis: applications to developmental research. Child Dev 85:842-860. https://doi.org/10.1111/cdev.1216

Yuan Y, MacKinnon DP (2009) Bayesian mediation analysis. Psychol Methods 14:301-322. https://doi.org/10.1037/a0016972

\section{Publisher's Note}

Springer Nature remains neutral with regard to jurisdictional claims in published maps and institutional affiliations. 